Santa Clara University

Scholar Commons

Women's and Gender Studies

College of Arts \& Sciences

$2-1-2006$

\title{
Embodied Knowledge: Writing Researchers' Bodies Into Qualitative Health Research
}

Laura L. Ellingson

Santa Clara University, lellingson@scu.edu

Follow this and additional works at: https://scholarcommons.scu.edu/gender

Part of the Communication Commons, and the Feminist, Gender, and Sexuality Studies Commons

\section{Recommended Citation}

Ellingson, L. L. (2006). Embodied Knowledge: Writing Researchers' Bodies Into Qualitative Health Research. Qualitative Health Research, 16(2), 298-310. https://doi.org/10.1177/1049732305281944

https://doi.org/10.1177/1049732305281944

This Article is brought to you for free and open access by the College of Arts \& Sciences at Scholar Commons. It has been accepted for inclusion in Women's and Gender Studies by an authorized administrator of Scholar Commons. For more information, please contact rscroggin@scu.edu. 
Embodied Knowledge: Writing Researchers' Bodies into Qualitative Health Research

\author{
Submitted to \\ Dr. John Engel, Editor "Pearls, Pith, and Provocation" section \\ and \\ Dr. Janice Morse, Editor, Qualitative Health Research
}

\author{
Laura L. Ellingson, Ph.D. \\ Assistant Professor of Communication \\ Department of Communication \\ Santa Clara University \\ Arts \& Sciences Bldg. \\ 500 El Camino Real \\ Santa Clara, CA 95053 \\ Phone: (408) 551-7056 \\ Fax: (408) 554-4913 \\ Email: lellingson@scu.edu
}

Laura L. Ellingson, Ph.D. is Assistant Professor of Communication at Santa Clara University, Santa Clara, California, USA.

An earlier version of this essay was awarded a Top Four Paper Award by the Ethnography Division of the National Communication Association (NCA) and presented at the 2001 NCA convention, Atlanta, GA, USA. The author wishes to thank Dr. Carolyn DiPalma for her feedback on the initial draft. 


\begin{abstract}
Embodied knowledge: Writing researchers' bodies into qualitative health research
\end{abstract}

After more than a decade of post positivist health care research and an increase in narrative writing practices, social scientific, qualitative health research remains largely disembodied. The erasure of researchers' bodies from conventional accounts of research obscures the complexities of knowledge production and yields deceptively tidy accounts of research. Qualitative health research could benefit significantly from embodied writing that explores the discursive relationship between the body and the self and the semantic challenges of writing the body by incorporating bodily details and experiences into research accounts. Researchers' bodies can be represented through incorporating autoethnographic narratives, drawing on all of the researcher's senses, interrogating the connections between researchers' bodily signifiers and research processes, and experimenting with the semantics of self and body. I illustrate opportunities for embodiment with excerpts from an ethnography of a geriatric oncology team and explore implications of embodied writing for the practice of qualitative health research.

Key Words: embodiment, research writing, qualitative methods, feminist theory, health care 
My own sense of embodiment keeps me deeply rooted in the awareness that knowledge is not produced by the disembodied voices that speak in official accounts of research in professional journals and books, but by researchers whose bodies unavoidably influence all aspects of the research process (Author, 1998). I became interested in conducting health communication research because I could no longer ignore my troublesome body. As I approach the fifteenth anniversary of the biopsy that confirmed my diagnosis with osteogenic sarcoma of the right distal femur (bone cancer in my right thigh), I continue to live with chronic pain in my rebuilt leg. The pain, along with prominent scars, swelling, skin and muscle grafts, titanium rods, artificial knee joint, tendonitis, and limp, make it impossible for me to consider my body irrelevant or inconsequential to any aspect of my life, including my research on health care teamwork and provider-patient communication. While my body is particularly unruly, all researchers have bodies that should be acknowledged.

In this essay, I explore how and why researchers' bodies are erased in published studies within the field of health research, particularly in qualitative social science, and discuss the implications of this practice. The field of health care is particularly appropriate as a site for acknowledging the embodied production of knowledge because of its focus on members of the “community of pain" (Frank, 1995) whose own bodies are marked by illness or injury. With the "narrative turn" in social sciences, health, and education, positivist assumptions about researcher neutrality and objectivity have been decentered or (in some venues) eschewed in favor of realistic positioning of scholars as imperfect social actors (Denzin, 1997). However, even with the embracing of qualitative methods and the broadening of academic writing conventions (e.g., permitting or requiring use of first person rather than passive voice) by many contemporary 
health care researchers and journals, consideration of the body of the researcher remains largely absent from accounts of such research. Embodied narrative and interpretive health care research in this vein is largely segregated in edited collections (e.g., Harter, Japp, \& Beck, 2005) or journals whose focus is on interpretive methodology rather than health care (e.g., Qualitative Inquiry, Journal of Contemporary Ethnography). After more than a decade of post positivist qualitative health care research writing and an increase in "creative analytic" writing practices (Richardson, 2000), social scientific reports remain largely disembodied.

I contend that the erasure of researchers' bodies from conventional accounts of research obscures the complexities of knowledge production and yields deceptively tidy accounts of research. Further, I propose that the field of qualitative health research could benefit significantly from embodied writing by reflexive researchers whose bodies are implicated as sites of knowledge production. I draw upon a range of feminist and postmodern theorists as I describe the discursive relationship between the body and the self, the semantic challenges of writing the body, and some suggestions for incorporating the body into accounts of research. Examples from one of my own research projects, an ethnography of an interdisciplinary geriatric oncology team, provide illustration (Author, 2005). I conclude with a discussion of how embodied writing of qualitative research would enrich the field of health research.

\section{The Discursive Body}

Butler (1999) points out that bodies are actually produced through discourse; they do not have materiality totally apart from these discourses. She writes that "there is no reference to a pure body which is not at the same time as further formation of that body" (p. 240). Whether I am conforming to the established norms for my performance (e.g., femininity, heterosexuality) or not, I am judged by discursively constructed standards. If I am outside the boundaries of 
normalcy, I become a referent for the normal, an example of what is wrong that serves to affirm what is correct. The repeated performance of embodied identities such as gender or ethnicity denies their constructed (i.e., not inevitable or natural) status.

Performativity is thus not a singular 'act' for it is always a reiteration of a norm or set of norms, and to the extent that it acquires an act-like status in the present, it conceals or dissimulates the conventions of which it is a repetition (Butler, 1999, p. 241).

People do not choose appropriate behavior out of a desire to follow cultural rules; instead, the appropriate behavior is actually produced by the rules. That is, whether or not we are following the (often unstated or obscured) norm, we are always responding to and reinforcing social power constituted in normative performance. The act of performing oneself is naturalized by the obscuring of the fact that gender, ethnicity, or other categories of identity are repeated discursive and material (and therefore mutable) performances rather than fixed facets of existence. The preferred Western political reading of bodies historically has been one of a fixed, defined self: the privilege given to form, solidity, optics and fixity in the history of the west has, in effect, delayed us from developing alternative models of identity which would treat flow or the indefinite in its own terms, and not simply as a stage en route to a new developmental fixity (Battersby, 1999, p. 348).

Of course, not all bodies are discursively constructed in the same way: "Feminists have stressed that the generic category 'the body' is a masculinist illusion. There are only concrete bodies, bodies in the plural, bodies with a specific sex and colour" (Grosz, 1999, p. 270). The plurality of embodiment was ignored by Foucault whose theory of knowledge and power "treats the body throughout as if it were one, as if the bodily experiences of men and women did not differ and as 
if men and women bore the same relationship to the characteristic institutions of modern life" (Bartky, 1997, p. 131-132).

Theorists and researchers must consider how material bodies and the discourses which surround and permeate them relate by exploring how "the material and discursive are mutually determining" in specific contexts (Balsamo, 1999, p. 278). Foucault (1977) argues that truths come to be accepted and the process of their becoming "common sense" obscured because of power. Body norms are discursively constructed and performed in certain ways (and then the production obscured) in support of configurations of power that are the result of specific historical events and contingencies. Thus female bodies are defined to uphold masculine power, bodies of color defined in such a way as to uphold white privilege, LGBT or queer bodies defined to reinforce heteronormativity, and disabled and ill bodies defined to invent and privilege healthy bodies. Likewise, the definition of researchers' bodies as absent and inconsequential upholds their power over their participants.

The Bodiless Health Care Researcher

Researchers have used the power of academic discourse to define their own bodies as essentially irrelevant to the production of knowledge (Denzin, 1997). The performance of “disembodied researcher" has been repeated for so long that it functions as a set of naturalized norms that privilege a masculine mode of being. Western culture has continually reaffirmed the mind/body split and the association of male or masculine with mind and female or feminine with body (e.g., du Pre, 2005). Since the production of knowledge has traditionally been defined as the province of men, bodily knowledge has been systemically denied as oxymoronic; indeed, "it is as if 'facts' come out of our heads, and 'fictions' out of our bodies" (Simmonds, 1999, p. 52). 
Qualitative health research is virtually bodiless. One might think that health research is all about bodies - health care providers' bodies, patients' bodies, patients' companions' bodies. Traditionally, health communication research has focused on three main areas of research: doctor-patient [or patient-caregiver] communication, health information dissemination, and social support (Geist-Martin, Sharf, \& Ray, 2003; Sharf, 1993), all of which involved embodied actors caring for (or encouraging others to care for) their own and others' bodies in highly specific ways. Yet, there is little embodiment in the accounts of research. Research reports typically are written following strictly social scientific or medical conventions in which the author's agency is obscured via passive voice (e.g., the data were collected...) or represented through a sanitized "I" who reports having taken actions without describing any details of the body through which the actions were taken. In the past twenty or so years, journals such as Qualitative Health Research and Health Communication have encouraged qualitative researchers to use first person voice in writing and to own up to relevant aspects of one's identity (e.g., my identity as a cancer survivor; Author, 2003). Despite the "narrative turn" that has made qualitative research more credible to the medical and allied health communities and expanded the options for writing conventions (e.g., Denzin \& Lincoln, 2000), the articles, reports, and essays in interdisciplinary health care theory and research continue to omit details of their authors' embodied being as they relate to research processes and findings.

The invisibility of researcher bodies in accounts of qualitative health research limits our understanding of communication in health care contexts. Disembodied prose comes from nowhere, implying a disembodied author (Haraway, 1988). It is the privilege of the powerful to leave their bodies unmarked; research accounts in health care tend to reflect social science norms that frame the researcher's personality, body, and other sources of subjectivity as irrelevant. 
Thomson (1997) points out that unlike earlier periods of history during which visible signifiers or markers conferred prestige, today it is the privilege of being unmarked, of having one's own positionality obscured as the norm, that signifies power. White bodies, for example, are rarely noted by authors, whereas bodies of people of color are marked in texts as "different" from the ultimate control group of whiteness (Nakayama \& Krizek, 1995). Members of marginalized groups recognize that bodies are always political and cannot be separated from the self that produces knowledge (e.g., Davis, 1990); bodies are not neutral, but rather "maps of the relation between power and identity" (Rose, 1999, p. 361). When health care researcher's bodies remain unmarked - and hence naturalized as normative - they reinscribe the power of scholars to speak without reflexive consideration of their positionality, while others' voices remain silent or marginalized by their marked status.

The Semantics of Writing the Body

Disembodied writing is intertwined not just with academic writing conventions but with language itself. One important implication of the discursive construction of bodies is that our standpoints and bodies are not apart from our languaging of them. The meanings of our bodies always will be a joint construction among researchers and those who encounter our embodied descriptions: "[W]hen we try to name our bodily experiences, we are always involved in a dialogue" (Marshall, 1999, p. 71). The naming involves texts we have read, conversations we have shared, cultural beliefs we hold about our bodies, and many other influences upon our stores of language. We do not pull words from nowhere; we draw from language reference points in constructing our descriptions and labels. Discussing traditional, positivist approaches to writing, Trinh argues that, "In the passage from the heard, seen, smelled, tasted, and touched to the told and the written, language has taken place" (p. 263). Once language has taken place, 
meaning is created, assigned, even imposed upon the body, and we need to acknowledge that our languaging of experience and ideas cannot be thought of as somehow reporting pure bodily experience, nor purely disembodied knowledge.

The privileging of the mind over the body is deeply engrained in Western cultures. The invisibility of researchers' bodies is a product of the mind/body mentioned previously that posits “a clear division between mind, equated with self, experienced as proactive and unthreatening, and body, experienced as potentially troublesome. .." (Marshall, 1999; p. 71). The body is thus the (potentially unruly) property of the (higher) mind/self. An alternative feminist perspective bridges and blurs the boundary between the mind and body: "[I]nstead of the body being positioned as a bar to knowledge, knowledge is produced through the body and embodied ways of being in the world" (Price \& Shildrick, 1999, p. 19). Trinh (1999) suggests that "we do not have bodies, we are our bodies ... We write - think and feel - (with) our bodies rather than only (with) our minds or hearts" (p. 258; emphasis in original). For Trinh, the body is not a possession of higher mind, to be manipulated and controlled to serve the brain; the body and the person/self are one. The researcher's body is just as constructed and discursively inscribed with cultural meanings as any other body; however, language conventions make it difficult to include the body as the self, rather than the wholly-owned subsidiary of the self.

In addition to being owned by the mind/self, the body is also portrayed by language as a fixed entity, a static material object. Theorizing the body must take into account that biology is not fixed or determined. For Birke (1999), the body must be seen as changeable and "transformable" (p.45), not only in its cultural meanings and surface inscriptions, but within itself as well. We can think of interior bodily processes as performative, as present in the 
language we use to name and describe them, and therefore alterable. When researchers write our bodies in our health research, we must write from a dynamic understanding of bodies in flux.

Further complicating the possibility of writing the body, consciousness of the body varies by the filter through which it is experienced or perceived, and certain angles are socially privileged. That is, "[t]he body becomes visible as a body, and as a female body, only under some particular gaze - including that of politics" (Riley, 1999, p. 224). People's experiences of their bodies vary according to which factors of identity are relevant, problematic, or the focus of others' judgments. Marshall (1999) uses her own experience of being pregnant to point out that the body is not always experienced the same way. She is a woman biologically, but she does not always, at all times, experience her body specifically as female. Nor was she always consciously pregnant, during her pregnancy; at times, this state was not germane to what she experienced. Thus when writing her body, Marshall opens the possibility of writing from multiple positions of consciousness within the lived experience of variation in embodiment. To incorporate fluidity of bodies into research would seriously challenge social scientific norms. At the same time, it would necessitate more play with language, since the body is semantically fixed as well as owned by the mind.

All of these feminist perspectives on the difficulty of languaging the body, writing the body, embracing multiple modes of embodiment, and eschewing fixed, disembodied reasoning in favor of highlighting the messiness of research and writing have influenced my ideas about how to write my body. Writing the researcher's body as (part of) the text is one way to demonstrate the interconnectedness of the research and writing processes. When the body speaks in this way, it incorporates lived experience in a way that is impossible in detached prose. 
In my own ethnographic work, I strive to bring my body into my research as a site of knowledge production. Coffey (1999) argues that fieldwork is an embodied practice and that the researcher's body - where it is positioned, what it looks like, what social groups or classifications it is perceived as belonging to - matters in the production of ethnographic accounts. I propose extending her argument to specify that researchers' bodies matter regardless of methodology. In this section, I will explore opportunities to incorporate autoethnographic narratives in "layered accounts" of research (Ronai, 1995), as well as three ways in which researchers' bodies could be brought into more traditionally structured qualitative health research accounts: drawing on all of the researcher's senses, interrogating the connections between researchers' bodily signifiers and their research processes, and engaging in serious play with the semantics of the self and body "ownership."

One way to position the body as producing knowledge is to write autoethnographically about the research process. Rather than (or in addition to) structuring such accounts as freestanding narratives, short narratives about the researcher's experiences in the field and reflections could be incorporated into a report of qualitative data using a layered organization. Ellis and Bochner (2000) describe autoethnography as revealing multiple layers of consciousness, connecting the personal to the cultural... [autoethnographers focus] outward on social and cultural aspects of their personal experience; then, they look inward, exposing a vulnerable self that is moved by and may move through, refract, and resist cultural interpretations (p. 739).

Autoethnography blurs the lines between sciences and humanities (e.g., Author, 1998; Ellis \& Bochner, 2000) and problematizes the differentiation between researcher and researched (DeVault, 1990; Mies, 1983; Reinharz, 1992). Narrative and autoethnographic methods 
acknowledge the dialogic construction of patients' constructions of meaning of their illness with researchers' own embodied experiences (Frank, 1995). Rather than simply the narrator or reporter of findings, the researcher is the main character of a story that parallels the academic narrative contained in the research report. In layered accounts, researchers alternate sections of an article that is written using social science conventions (i.e., citation of relevant research and theory, presentation of a research question, explanation of methods) with brief narratives that show rather than tell about aspects of the research (Ronai, 1995); alternatively, such narratives can be placed at the beginning or end of the conventional analysis (e.g., Ellis 1993).

Autoethnographic narratives (potentially) offer embodied details, celebrate the author's position, problematize the production of knowledge, and reveal the profane in the sacred processes of research. In addition to data collection experiences, I urge researchers to consider writing (whether analytic or narrative) as also a deeply embodied process. My body, fraught with pain and nausea while recovering from major surgery, made contemplation of my bodily experiences emotionally taxing, thus shaping many of my stylistic and substantive choices as I constructed my account (Author, 2005). Writing is done with fingers and arms and eyes-it is an embodied act, not mental conjuring, and we should reflect on the experience of writing our research just as we reflect on our experience of being at the research site.

In an autoethnographic account of an interdisciplinary geriatric oncology program (Author, 1998, 2005), my embodiment is most evident when I provide vivid descriptions of my body in my roles of researcher and as a patient (Frank, 1995). The following is an example from my clinic fieldnotes.

The pungent smell of decay hits me as I walk into the examination room, and I struggle to keep the smile on my lips and all traces of repugnance masked. A dark, oily stain on Mr. 
Holmes' golf shirt hints at a leak of some sort, a feeding tube probably, that is the source of the odor. It smells like a combination of excrement and something that rotted in the back of the refrigerator. In the small examination room, little air circulates, and the stench is overpowering. I fight the impulse to cover my nose and look to Carlena [social worker] for cues. (Author, 2005, p. 86)

The odor affected my body, and I garnered insights about the patient and health care team members as we all coped with the unpleasant problem. Tales of my embodied experience in the clinic demystify the process of my research and writing because they make it clear that my body could not be separated from and dominated by my mind's logical perspective.

Despite their value as embodied tales, autoethnographic narratives are not always the genre of choice for researchers, and of course, personal writing is not welcome in many academic venues, even when layered into a more conventional report. I now explore three ways that researcher's bodies can be represented in conventionally written qualitative research reports.

First, as other qualitative methodologists have suggested, researchers could pay more careful attention to all of their senses as they conduct research and include relevant details in the “thick description" of their qualitative findings (Conquergood, 1991; Geertz, 1973). Haraway (1989) posits that Western science privileges optical knowing as the dominant epistemology; seeing is believing. However, I smelled, tasted, touched, and heard the clinic in addition to seeing it, and I documented those sensations as well, enriching the analytic portion of my account. For example, hunger, fatigue, and allergy attacks made me impatient and less attentive during some periods of observation, and I remarked on this in my fieldnotes. Also, because I live with chronic knee pain, I had to leave the clinic when I could no longer stand, which affected my understanding of the clinic by causing me to miss out on some interactions. I wrote 
too about the chill of the air conditioner, the smell of the photocopier toner, the taste of pizza in the break room, and the dizzying cacophony of voices as ten or more health care professionals worked in a small area in the backstage of the clinic. In my detailed explanation of the power hierarchy of the clinic as it related to sharing limited resources (e.g., computers, chairs, counter space), I wrote:

As a person of provisional status in the clinic, I vacated a chair anytime I saw clinic personnel looking for a place to sit; I was willingly complicit in order to preserve my access to the clinic. This pecking order of privilege was carefully maintained. . (Author, 2005, p. 125)

Whose tired bodies get to sit and whose must stand is important information about the daily enactment teamwork in the clinic. My physical complicity with the unstated rules demonstrates their power. This strategy of using all one's senses to record data is obviously relevant to fieldwork, but researchers should use all of their senses regardless of methodology. For example, a researcher investigating physician-patient communication in a public clinic may give out surveys or conduct interviews in the waiting room. Noting the details of temperature, smell, appearance, and the researcher's physical experience of the waiting room provides important clues about the organizational context in which patients receive care that could help interpret responses about satisfaction with physicians' care.

Martin's (1995) study of the cultural construction of the (meanings of the) immune system is an exemplar of a qualitative health project in which the author's body and senses are part of the text, albeit intermittently. Martin makes her body part of the process of producing and languaging her findings for her audience. Speaking of her fieldwork, Martin says, “...I felt an imperative to place myself bodily in these contexts, to feel viscerally the threats as well as the 
delights of working and organizing to fight this major epidemic [AIDS] ...” (p. xv). For example, Martin describes the process of bathing a man with AIDS who is covered with feces as water seeps into her protective gloves. Despite her extensive knowledge of risk factors, transmission, and protection, she at times became quite anxious about contracting AIDS. Describing the process of touching this man's contaminated bodily fluids and her own fears is a powerful way to bring her body in as she discusses the public's fear of HIV exposure.

Both my and Martin's accounts demonstrate that engaging multiple senses in fieldwork, and then incorporating sensuous details into written accounts calls into question the mind/body split. Moving away from a wholly optical knowing to one that values smell and touch, for example, invokes the reality of (messy, uncontrollable) bodily experiences and disrupts the researcher's privilege of the power of disembodied viewing.

A second strategy for embodying analytic accounts is to interrogate the specific ways which bodily inscriptions affected a researcher's process. Categories of culture such as gender, age, race, class, sexuality, and disability may be limited by essentialist definitions, but they provide a useful starting point for exploring the impact of people's bodies on their research opportunities and challenges. It is not sufficient for researchers to simply state up front the categories to which they belong. Researchers must interrogate the ways in which participants related to them in fieldwork, the willingness of strangers to comply with a request to complete a written survey, the ease with which one obtained access to a private corporation to conduct research interviews with employees, the assumptions made about how a research report should be composed, and so on. These factors will impact directly the methods utilized and the data compiled. Something as simple as women not wanting to go alone to interview male research participants in their homes, for example, impacts research design significantly. Instead of 
dismissing these as peripheral concerns, they could be brought in to a discussion of how research practices reflect, reinscribe, and/or subvert social power structures that shaped and are shaped by our bodies and their signifiers.

In my own research, my misshapen leg and knee brace proved both a point of connection with oncology patients and at times drew unwanted attention that affected my participant observation. I am marked physically as a patient even when I want to be perceived as a researcher, demonstrating the slipperiness of categories. In resisting a single category, I embody the knowledge that there is more than one way to know the clinic.

It bears mentioning that I walk with a pronounced limp due to reconstructive surgeries for bone cancer in my right leg, and patients and companions often asked about it. I answered all questions about my personal health history and status as a researcher but avoided discussing what I was studying, except to say that I "wanted to understand how patients and team members communicated with each other." While I did not announce my identity as a cancer survivor to every patient, I did reveal it when asked about my limp and leg brace because I believe it would have been unethical to deceive patients and their companions about my survivor status. Patients and companions often said that they were glad that I had some idea of what they were experiencing... (Author, 2003, p. 115) My impaired body shaped how people understood and responded to me. Likewise, my whiteness eased my initial acceptance into a team of health care providers who were all white people. The team members presumably would have welcomed a person from a differing ethnicity, but the process of incorporating that person into the daily routine would have required more conscious accommodation. My unearned social privilege helped me to fit in and thus reflects power. I would have known the team very differently if I had been from another racial 
or ethnic group, not just because they would have perceived me differently, but also the reverse. My consciousness of my body-marked-as-patient would have been impacted greatly if racial or ethnic signifiers also marked me as unlike the team members.

A third way to bring the body into analytic writing is to wrestle with the semantics of the body, including framing the body as self rather than as property of the mind/self and portraying the body as fluid and changeable. Many theorists and researchers have struggled with the problem of language as they seek to demonstrate that "Our body-boundaries do not contain the self; they are the embodied self" (Battersby, 1999, p. 355; emphasis in original). When I refer to "my body" in my writing, I reaffirm the existence of a self that owns or supervises a (troublesome, non-knowing) body. The difficulty lies in writing intelligibly while also reflecting the embodied nature of knowledge in our body-selves. Trinh (1991), for example, discusses the "subjectivity of a non-I/plural I" (p. 192) as a strategy to counter hegemonic Western conceptualizations of the self as a single, unitary, fixed (mental) entity that owns a body, independently of which it creates knowledge. Along similar lines, Irigaray (1980) invokes you/I, $\mathrm{I} / \mathrm{you}$, and you/me in her discussion of the need for plurality of identity rather than reaffirmation of dichotomies (e.g., male/female, culture/nature) through the pervasive masculine standards by which sexed bodies are judged in Western cultures.

I struggle with language, possessing my static body instead of being it, but at the same time trying to problematize that linguistic stasis and ownership. The only example of blurring the mind and body I have been successful in gaining editorial approval for was in the autoethnography section of my ethnography: "the sharp sound of pagers rips open a scab I hadn't known still lingered on my psyche, and I gasp as the blood/memory flows" (Author, 2005, p. 95). This move was easier to accomplish because it was in the context of narrative writing; 
such a strategy would disrupt the reader far more if it were placed in a grounded theory analysis of communicative practices, for example. Resisting the dichotomy of analysis/narrative is a powerful correlate to linguistic resistance of the mind/body split. Such bodily reactions as the force with which my memory entered my consciousness provide important insights into data on how patients and health care providers construct the meanings of living with and treating illness. I encourage researchers to (gently) push the boundaries of writing conventions by trying out unusual phrasing of self and body when doing so would enhance the meaning they are seeking to convey.

\section{Implications}

Embodied writing of qualitative health research would mark the privileged bodies of researchers as integral to the development of findings and theory. Subjecting existing power structures to scrutiny is political work. In this way, "[r] ather than try to 'reflect truth' in a traditional fashion, research itself becomes an instrument for emancipation or intervention. It generates a critical posture toward the taken-for-granted" (Gergen, 1994, pp. 136-137).

Resisting the mind/body split by incorporating researchers' bodies into research articles is not easy, but these suggestions are a starting point towards troubling the taken-for-grantedness of the norms of health care and of qualitative health research. If change in the power structures of health care is going to be accomplished, the workings of power, and researchers' complicity with them, must first be marked and interrogated. We cannot change what we consider natural.

Beyond subjecting the naturalized norms of research to scrutiny, embodying research as I have discussed here offers three important implications for making sense of health care from both practitioners' and patients' perspectives. First, acknowledging the body reaffirms researchers' common humanity with patients by keeping researchers on the same (messy, 
imperfectly controlled) level where patients must live. It reminds us that we all will join the "community of pain" eventually and that compassion for those who suffer must remain integral to our analysis and theorizing of their experiences. Second, mention of researcher's bodies points to the expanding (albeit still not broad enough) group of people whose perspectives are and/or should be represented within the interdisciplinary health fields. Marking our ethnicity, nationality, gender, sexuality, health status, and other aspects of our identities draws attention to the plurality of bodies who are both researchers and researched. Third, including researchers' bodies is an integral part of researchers' reflexivity, wherein we continually remind ourselves that our work and our words are grounded in the specific standpoints that we occupy. Rather than apologizing for our subjectivity or simply stating our "biases," we should instead carefully consider how ourselves and our experiences influence our research processes (Author, 1998; Ellis, 2004).

\section{Conclusion}

In writing disembodied, systematic accounts (even in constructing coherent narratives) we gain mastery over material; we contain our findings in careful prose, numbers, tables, models, and theories. When we do this, we often detach ourselves from the knowledge we produce, and we deny our bodily vulnerability. Writing coherent accounts of our research allows us to gain social approval by other academics and to contribute to bodies of knowledge; both of these are valuable goals. However, this approach to writing research also limits us. A more embodied field of qualitative health research would maintain more permeable boundaries, be more difficult to categorize, and offer less certainty and more vulnerability. Researchers would have to address our fears of illness, death, and bodies out of control instead of staying detached and ignoring our bodies (and others' bodies). Embodiment is critical to qualitative health research because the 
body is the site of knowledge production; the mind is not apart from the body, but part of it. Producing separate creative analytic accounts (Richardson, 2000), such as narratives, poems, and performances (e.g., Gray \& Sinding, 2002) is vital, but such interpretive work must not substitute for embodying social scientific, qualitative health care research. Researchers' bodies can be a bridge that spans the chasms between mind and body and between narrative and analysis, offering exciting possibilities for greater understanding of health care. 


\section{References}

Author (1998), Author (2003), Author (2005)

Balsamo, A. (1999). Forms of technological embodiment: Reading the body in contemporary culture. In J. Price and M. Shildrick (Eds.), Feminist theory and the body: A reader (pp. 278-289). New York: Routledge.

Bartky, S. L. (1997). Foucault, femininity, and the modernization of power. In K. Conboy, N. Medina, \& S. Stanbury (Eds.), Writing on the body: Female embodiment and feminist theory, (pp. 129-154). New York: Columbia University Press.

Battersby, C. (1999). Her body/her boundaries. In J. Price and M. Shildrick (Eds.), Feminist theory and the body: A reader (pp. 341-358). New York: Routledge.

Birke, L. (1999). Bodies and biology. In J. Price and M. Shildrick (Eds.), Feminist theory and the body: A reader (pp. 42-49). New York: Routledge.

Butler, J. (1999). Bodies that matter. In J. Price and M. Shildrick (Eds.), Feminist theory and the body: A reader (pp. 235-245). New York: Routledge.

Coffey, A. (1999). The ethnographic self: Fieldwork and the representation of identity. Thousand Oaks, CA: Sage.

Conquergood, D. (1991). Rethinking ethnography: Towards a critical cultural politics. $\underline{\text { Communication Monographs, }} \underline{\text { 58, }}$ 179-194.

Davis, A. Y. (1990). Women, culture, \& politics. New York: Vintage.

Denzin, N. K. (1997). Interpretive ethnography: Ethnographic practices for the 21st century. Thousand Oaks, CA: Sage. 
Denzin, N. K., \& Lincoln, Y. S. (2000). Introduction: The discipline and practice of qualitative research. In N. K. Denzin \& Y. S. Lincoln (Eds.), Handbook of qualitative research (2nd ed., pp. 1-28). Thousand Oaks, CA: Sage.

DeVault, M. L. (1990). Talking and listening from women's standpoint: Feminist strategies for interviewing and analysis. Social Problems, 37, 96-116.

du Pre, A. (2005). Communicating about health: Current issues and perspectives $\left(2^{\text {nd }}\right.$ ed.). Boston: McGraw Hill.

Ellis, C. (1993). 'There are survivors': Telling a story of sudden death. The Sociological Quarterly, 34, 711-730.

Ellis, C. (1997). Evocative autoethnography: Writing emotionally about our lives. In W. Tierney \& Y. Lincoln (Eds.), Representation and the text: Reframing the narrative voice, (pp. 115-139). Albany, NY: SUNY Press.

Ellis, C. (2004). The ethnographic I: A methodological novel about autoethnography. Walnut Creek, CA: AltaMira.

Ellis., C., \& Bochner, A. P. (2000). Autoethnography, personal narrative, reflexivity: Researcher as subject. In N. K. Denzin, \& Y. S. Lincoln (Eds.), $\underline{\text { Handbook of qualitative }}$ research, second edition, (pp. 733-768). Thousand Oaks, CA: Sage.

Foucault, M. (1977/1996). Nietzsche, genealogy, history. trans. D. Bouchard \& S. Simon. In D. Bouchard (Ed.), Language, counter-memory, practise (pp. 139-164). Ithaca, NY: Cornell University Press.

Frank, A. W. (1995). The wounded storyteller: Body, illness, and ethics. Chicago: University of Chicago Press.

Geertz, C. (1973). The interpretation of cultures: Selected essays. New York: Basic Books. 
Geist-Martin, P., Ray, E. B., \& Sharf, B. F. (2003). Communicating health: Personal, cultural, and political complexities. Belmont, CA: Wadsworth.

Gergen, K. J. (1994). Realities and Relationships: Soundings in Social Construction. Cambridge, MA: Harvard University Press.

Gray, R., \& Sinding, C. (2002). Standing ovation: Performing social science research about cancer. Walnut Creek, CA: AltaMira.

Grosz, E. (1999). Psychoanalysis and the body. In J. Price and M. Shildrick (Eds.), Feminist theory and the body: A reader (pp. 267-271). New York: Routledge.

Haraway, D. (1988). Situated knowledges: The science question in feminism and the privilege of partial perspective. Feminist Studies, 14, 575-599.

Haraway, D. (1989). Primate visions: Gender, race, and nature in the world of modern science. New York: Routledge.

Harter. L. M., Japp, P. M., \& Beck, C. S. (Eds.). (2005). Narratives, health, and healing: Communication theory, research, and practice. Mahwah, NJ: Lawrence Erlbaum.

Irigaray, L. (1980). When our lips speak together. Trans, C. Burke. Signs: Journal of Women in Culture and Society, 6, 69-79.

Marshall, H. (1999). Our bodies, ourselves: Why we should add old fashioned empirical phenomenology to the new theories of the body. In J. Price and M. Shildrick (Eds.), Feminist theory and the body: A reader (pp. 64-75). New York: Routledge.

Martin, E. (1995). Flexible bodies : Tracking immunity in American culture-From the days of polio to the age of AIDS. Boston: Beacon Press.

Nakayama, T. K., \& Krizek, R. L. (1995). Whiteness: A strategic rhetoric. Quarterly Journal of Speech, 81, 291-309. 
Price, J., \& Shildrick, M. (1999). Part one: Introduction. In J. Price and M. Shildrick (Eds.), Feminist theory and the body: A reader (pp. 17-20). New York: Routledge.

Reinharz, S. (1992). Feminist methods in social research. New York: Oxford University Press. Richardson, L. (2000). Writing: A method of inquiry. In N. K. Denzin \& Y. S. Lincoln (Eds.),

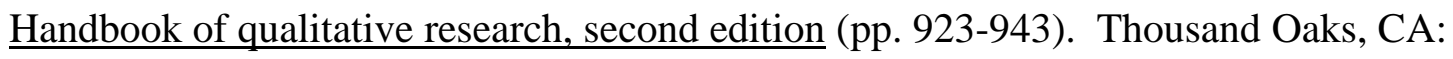
Sage.

Riley, D. (1999). Bodies, identities, feminisms. In J. Price and M. Shildrick (Eds.), Feminist theory and the body: A reader (pp. 220-226). New York: Routledge.

Ronai, C. (1995). Multiple reflections of childhood sex abuse: An argument for a layered account. Journal of Contemporary Ethnography, 23, 395-426.

Rose, G. (1999). Women and everyday spaces. In J. Price and M. Shildrick (Eds.), Feminist theory and the body: A reader (pp. 359-370). New York: Routledge.

Sharf, B. F. (1993). Reading the vital signs: Research in health care communication.

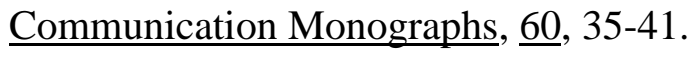

Simmonds, F. N. (1999). My body, myself: How does a black woman do sociology? In J. Price and M. Shildrick (Eds.), Feminist theory and the body: A reader (pp. 50-63). New York: Routledge.

Thomson, R. G. (1997). Extraordinary bodies: Figuring physical disability in American culture and literature. New York: Columbia University Press.

Trinh, T. M. (1991). When the moon waxes red: Representation, gender and cultural politics. New York: Routledge.

Trinh, T. M. (1999). Write your body: The body in theory. In J. Price and M. Shildrick (Eds.), Feminist theory and the body: A reader (pp. 258-266). New York: Routledge. 